\title{
ИСПОЛЬЗОВАНИЕ РЕГИСТРОВ НАСЕЛЕНИЯ ДЛЯ УЧЕТА И АНАЛИЗА НЕЗАРЕГИСТРИРОВАННЫХ БРАКОВ
}

\author{
ЕКАТЕРИНА ТРЕТЬЯКОВА, АЛЛА МАКАРЕНЦЕВА
}

\begin{abstract}
Рассматриваются возможности и ограничения использования регистров населения для изучения тенденций брачности, в фокусе внимания авторов находятся вопросы учета разных типов незарегистрированных браков. Описана европейская практика их оформления (зарегистрированнье партнерства, соглашения о сожительстве). Статья носит обзорный характер, в ней раскрываются особенности функционирования современных регистров населения в развитых странах, которые имеют богатые возможности для исследования демографического поведения населения. $K$ их преимуществам относятся покрытие всего населения региона, низкие издержки извлечения данных, актуальность данных и возможность проведения лонгитюдного анализа семейных отношений. Показаны основные методологические сложности использования регистров для учета незарегистрированных браков и пути их преодоления: использование информации об адресе проживания граждан, совместных детях. Выявлены различия между методологией регистров 6 разных странах, в том числе по учету иностранных граждан.

В статье представлен обзор зарубежных исследований, использующих даннье регистров для изучения института брака: для оценок распространенности незарегистрированных брачных союзов, их длительности, факторов формирования и прекращения, а также влияния пребывания 8 том или ином типе партнерства на репродуктивное поведение и продолжительность жизни.
\end{abstract}

Ключевые слова: источники данных, регистры населения, брачность, незарегистрированные браки, сожительства.

\section{ВВЕДЕНИЕ}

Современные регистры населения - один из важнейших источников демографических данных. Они используются для комплексного анализа естественного и миграционного движения населения, широко применяются в исследовании связей социальноэкономического и демографического развития, являются ключевым источником эмпирических данных для анализа наступлений событий жизни и верификации теории жизненного пути. В настоящей работе рассматриваются возможности и ограничения использования регистров населения для изучения тенденций брачности, а в фокусе внимания находятся незарегистрированные браки.

ЕКАТЕРИНА АЛЕКСЕЕВНА ТРЕТЬЯКОВА (tretyakova-ea@ranepa.ru), ИНСТИТУТ СОЦИАЛЬНОГО АНАЛИЗА И ПРОГНОЗИРОВАНИЯ РОССИЙСКОЙ АКАДЕМИИ НАРОДНОГО ХОЗЯЙСТВА И ГОСУДАРСТВЕННОЙ СЛУЖБЫ ПРИ ПРЕЗИДЕНТЕ РОССИЙСКОЙ ФЕДЕРАЦИИ, РОССИЯ.

АЛЛА ОЛЕГОВНА МАКАРЕНЦЕВА, ИНСТИТУТ СОЦИАЛЬНОГО АНАЛИЗА И ПРОГНОЗИРОВАНИЯ РОССИЙСКОЙ АКАДЕМИИ НАРОДНОГО ХОЗЯЙСТВА И ГОСУДАРСТВЕННОЙ СЛУЖБЫ ПРИ ПРЕЗИДЕНТЕ РОССИЙСКОЙ ФЕДЕРАЦИИ, Россия.

СТАТЬЯ ПОСТУПИЛА В РЕДАКЦИЮ В ИЮНЕ 2016 Г. 
Развитие института семьи находится в тесной связи с воспроизводством населения, рождаемостью условных и реальных поколений женщин. Без изучения тенденций формирования брачных союзов (зарегистрированных и незарегистрированных, первых и повторных, детных и бездетных) невозможно получить корректное представление о трансформации репродуктивного поведения современных мужчин и женщин. Между тем в ряду демографических процессов изучение брачности сталкивается едва ли не с самыми большими сложностями в получении эмпирической информации. По мере усложнения индивидуальных матримониальных биографий нехватка подходящих баз (содержащих не только текущие, но и ретроспективные данные обо всех типах союзов) ощущается особенно остро.

Переписи населения содержат слишком скудный перечень вопросов, не всегда позволяющий оценить даже распространенность незарегистрированных браков (как в России, например $\left.{ }^{1}\right)$. Специализированные выборочные обследования населения являются одним из наиболее популярных источников информации о брачности, так как позволяют собирать достаточно детальные сведения, однако к их недостаткам относятся небольшие размеры выборок (они редко превышают 10-15 тыс. респондентов), смещения характеристик выборочной совокупности относительно всего населения и невысокая достоверность ответов на сенситивные биографические вопросы. Традиционные данные органов, регистрирующих брак, могут представлять большую ценность для изучения процессов заключения и распада официальных браков, особенно, если перечень сопутствующих характеристик супругов достаточно обширен, а сами данные представлены в индивидуальном виде. Регистры населения представляют собой источник административных данных, особенностью которого является полнота учета населения, высокая достоверность ретроспективных данных, наличие информации не только о демографических событиях жизни конкретного индивида и членов его (ее) домохозяйства, но и об их социально-экономических характеристиках. Использование регистров для исследовательских целей возможно в тех странах, где они не просто существуют, но и налажена передача данных из них для нужд статистического учета и исследовательских запросов. Особенностью международного подхода к работе с регистрами является организация доступа к анонимизированным массивам индивидуальных данных, как правило, в формате реляционных баз. Кроме того, общей практикой является предоставление возможности объединения информации из регистров с переписями населения и другими источниками данных.

Настоящая работа носит обзорный характер, раскрывая особенности функционирования современных регистров населения. В России такого доступного для исследователей источника данных нет, поэтому он редко становится предметом научного интереса. Если обратиться к отечественной литературе, посвященной изучению незарегистрированных браков с помощью регистров населения, то данное поле оказывается практически неосвоенным. Немногие существующие работы посвящены в основном

\footnotetext{
${ }^{1}$ В российских переписях вопрос о регистрации брака фактически является подвопросом к факту состояния в браке, что приводит к отрицательным ответам респондентов, не идентифицирующих совместное проживание с партнером как «брак». Кроме того, отсутствуют дополнительные критерии (длительность союза). При такой методологии оценки распространенности явления оказываются некорректными.
} 
возможностям проведения анализа брачности и разводимости на основе данных российских ЗАГСов. В частности, Е.И. Иванова [Иванова 2012] провела анализ изменения учета населения, в том числе брачности и разводимости, в актах учета гражданского состояния с 1997 г. В результате исследования автором был предложен ряд мер по повышению эффективности современной системы текущего учета населения, среди которых следует выделить внесение в регистры сведений о месте постоянного жительства и продолжительности проживания в нем для лиц, вступающих в брак, а также регистрирующих рождение ребенка.

Ряд русскоязычных работ посвящен использованию данных регистров в переписях населения, в них отмечаются относительно более низкие издержки и высокая актуальность данных, предоставляемых регистрами населения [Клупт, Никифоров 2010; Пьянкова 2014]. В статье Л.В. Андриченко и М.А. Мещерякова проводится анализ использования данных регистров населения в переписях населения на примере Финляндии, Швейцарии и Белоруссии [Андриченко, Мещеряков 2012], рассматриваются возможности для создания централизованного регистра населения в России.

Г.Ш. Бахметова и А.А. Исупов рассматривали зарубежный опыт использования регистров населения для демографического анализа [Бахметова, Исупов 1999]. В их работе также есть обзор функционирования регистров по состоянию на конец XX века, способов получения и обработки информации из них, однако вопросы изучения незарегистрированных браков в ней не затрагиваются.

В целом можно отметить, что если вопросы изучения брачности и разводимости на основе регистров населения присутствуют в работах российских авторов, то проблематика учета и анализа незарегистрированных браков остается неизученной.

\section{РАСПРОСТРАНЕНИЕ И СПЕЦИФИКА РЕГИСТРОВ НАСЕЛЕНИЯ}

Начало использования регистров населения было положено в северных странах: еще в 1953 г. Исландия ввела первый единый централизованный государственный регистр населения. В период с 1964 по 1969 г. центральные регистры населения были учреждены во всех скандинавских странах: в 1964 г. в Норвегии, в 1967 г. в Швеции, в 1968 г. в Дании, в 1969 г. в Финляндии. В настоящее время централизованные регистры населения используются уже в большинстве европейских стран, однако наиболее полная информация предоставляется регистрами скандинавских стран (рисунок 1).

Стоит отдельно выделить систему учета населения Нидерландов, в которой отсутствует общий центральный регистр населения: локальные регистры находятся под ответственностью местных администраций, которые обмениваются данными в рамках единой онлайн-системы [Poulain, Herm 2013: 189]. При этом ведение локальных регистров населения началось в Нидерландах еще в 1850 г. Во многих странах, например в Германии, Греции, Италии, на Кипре и Мальте, региональные регистры населения функционируют автономно и не связаны в единую сеть. В Великобритании и Франции также существуют регистры населения, но в них не указывается место жительства, что делает невозможным учет сожительствующих пар по факту общего адреса их проживания. 


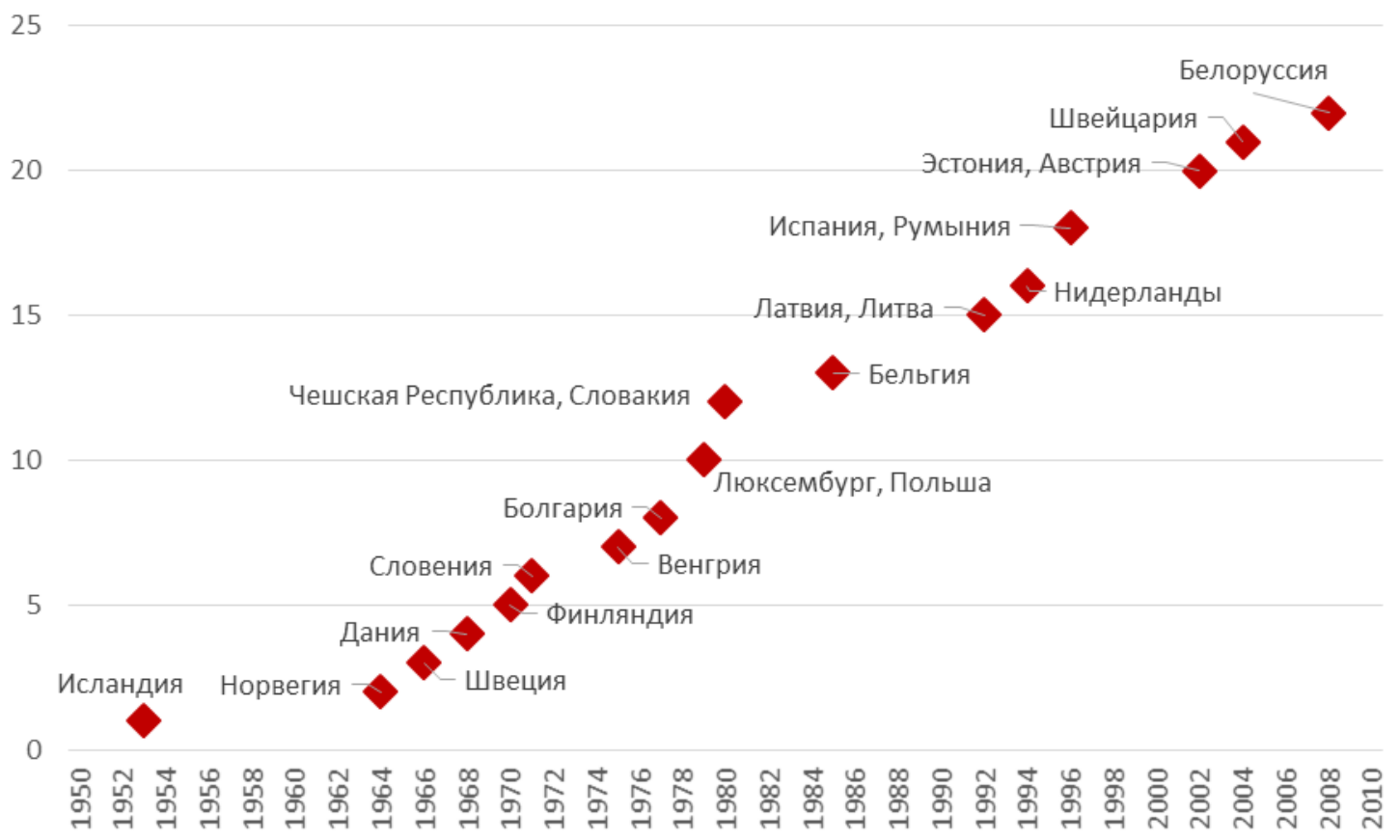

Рисунок 1. Перечень стран, использующих централизованные регистры населения

Источник: [Poulain, Herm 2013: 190].

Интересен также опыт Швейцарии, где статистический учет населения и домохозяйств строится на основе административных данных, данных унифицированных регистров населения общин и кантонов, данных автоматизированного регистра актов гражданского состояния Конфедерации, данных центральной миграционной информационной системы, а также данных информационной системы Федерального департамента иностранных дел. Сбор и унификация информации происходит с помощью платформы электронного обмена данными (SEDEX) благодаря персональным идентификационным номерам, присваиваемым гражданам.

Одним из базовых условий создания статистической системы, основанной на регистрах населения, является то, что каждому жителю страны присваивается уникальный идентификационный номер, который делает возможным построение связей между детьми и родителями, супругами и партнерами. Адрес проживания граждан можно проследить на протяжении многих лет, что делает возможным лонгитюдный анализ, в том числе брачнопартнерских отношений.

Еще с 1960-х годов ведется дискуссия о замене традиционной переписи населения переписями, основанными на данных регистров населения. Переписи на основе регистров охватывают все население, требуют значительно меньших как временных, так и денежных затрат и предоставляют наиболее актуальные данные. В переписях 2010-2011 гг. к данному способу учета уже обратились скандинавские страны, а также Австрия.

При использовании данных регистров населения в международных сравнениях следует помнить, что получаемые из них сведения нередко оказываются неполными либо несопоставимыми между странами. Главным источником расхождений являются различия в подходах к определению термина «сожительство» и способам учета сожительствующих 
пар. Это касается даже стран с наиболее продолжительной историей ведения регистров: например, в Норвегии пара может быть отнесена к проживающим совместно (cohabitating) только в случае наличия у нее общего ребенка, в то время как в Швеции и Финляндии для получения данного статуса достаточно факта постоянного совместного проживания и ведения общего хозяйства. Более того, в норвежский и голландский регистры населения включаются иностранные граждане (в Нидерландах с января 2014 г.), а в датском и шведском регистрах учитываются только резиденты этих стран.

В 1992 г. было проведено исследование достоверности данных регистров населения «3Bbis», в рамках которого гражданам задавались те же вопросы, которые входят в регистры населения. В результате исследования выяснилось, что данные регистров не учитывают 4\% мигрантов, 20\% детей, покинувших родной дом, 22\% домохозяйств, состоящих из пары, проживающей без регистрации брака [Poulain, Herm 2013: 196]. Допущение подобных неточностей происходит благодаря временному лагу, с которым административные офисы получают информацию о смене места жительства граждан.

А.И. Пьянкова отмечает, что данные регистров несколько завышают численность населения по сравнению с данными сплошного учета, так как часть населения после отъезда из страны не снимается с учета [Пьянкова 2014]. С данной проблемой столкнулись страны Балтии, когда в последнем раунде переписей провели сплошной опрос параллельно с получением данных из регистров. В результате сравнения выяснилось, что численность населения в Эстонии по данным регистров превышает численность населения по опросу на $4 \%$, в Литве - на 6\%, значительные расхождения были обнаружены и в Латвии.

При ретроспективном анализе необходимо учитывать, что до 1998 г. в Норвегии и до 1990 г. в Швеции молодые люди, которые временно жили вне родительского дома в связи с учебой или службой в армии, регистрировались по адресу проживания их родителей. И сегодня определение «совместного проживания» или «домохозяйства» является размытым, так как в регистры домохозяйств включаются лица, постоянно проживающие по определенному адресу даже в случае, если временно они проживают в другом месте. Согласно оценке Н. Кайлмана и Х. Брунборга [Keilman, Brunborg 1995], в результате доля пар, проживающих совместно без регистрации брака, занижается на $22 \%$. Кроме того, до 1998 г. в Швеции изменение места жительства граждан фиксировалось по дате получения заявления, а не по фактической дате, сообщаемой гражданами, что создавало временной лаг и могло приводить к расхождению данных с результатами опросов.

Также до недавнего времени в шведском и в норвежском регистрах указывался лишь номер дома, а не апартаментов, поэтому выделить совместно проживающие пары можно было лишь в случае наличия общих детей, связи с которыми фиксировались в регистре населения.

Еще одним существенным недостатком использования адреса постоянного проживания лиц для учета партнерских отношений является ограничение контингента лицами, официально зарегистрированными по месту их жительства. Отнюдь не все пары регистрируют новое место жительства непосредственно в момент переезда, один или оба партнера могут оставаться «прописанными» по другому адресу. Таким образом, оценка 
распространенности сожительств лишь на основе адреса проживания может оказаться значительно заниженной. Проведенное сравнение на базе шведского и норвежского регистров выявило около 30\% пар, проживающих совместно без регистрации брака, которые не были прописаны по одному адресу [Thomson, Eriksson 2013]. Данная проблема может решаться с помощью стимулирования населения к официальной регистрации факта совместного проживания, что применяется в Норвегии и о чем более подробно будет рассказано далее.

Важную роль в достоверности данных регистров оказывает и человеческий фактор: многим матерям-одиночкам более выгодно избегать регистрации своего партнера по общему адресу проживания, так как тем самым она может лишиться социальных льгот [Carlson et al. 2004; Perelli-Harris, Sánchez Gassen 2012].

Таблица 1. Оценка доли детей, рожденных вне зарегистрированного брака в Швеции: данные регистров против данных опросов, \%

\begin{tabular}{|c|c|c|c|}
\hline & \multicolumn{3}{|c|}{ Рождений по видам союзов } \\
\hline & вне союза (одинокие) & в сожительстве & в зарегистрированном браке \\
\hline \multicolumn{4}{|c|}{ 1974-1979 г2. } \\
\hline Опрос «Уровень жизни» ${ }^{2}$ & 3 & 39 & 58 \\
\hline Регистр населения & 6 & 29 & 66 \\
\hline \multicolumn{4}{|c|}{ 1980-1989 г2. } \\
\hline Опрос «Уровень жизни» & 3 & 50 & 47 \\
\hline Регистр населения & 6 & 40 & 54 \\
\hline \multicolumn{4}{|c|}{ 1987-1992 г2. } \\
\hline $\begin{array}{l}\text { Опрос «Рождаемость и семья» } \\
\text { (Fertility and Family Survey) }\end{array}$ & 5 & 45 & 51 \\
\hline Регистр населения & $71000-100$ & 42 & 50 \\
\hline Опрос «Уровень жизни» & $3^{1990-199}$ & 54 & 43 \\
\hline Регистр населения & 8 & 45 & 48 \\
\hline
\end{tabular}

Источник: [Thomson, Eriksson 2013: 1170].

Еще одно исследование, посвященное достоверности данных регистров, вышло в 2013 г. [Thomson, Eriksson 2013]. Оно основано на регистре поколений Швеции ${ }^{3}$, общем регистре населения, а также результатах переписей 1960-1990 гг. Согласно результатам работы, данные о месте регистрации жителей, полученные на основе регистров, соответствуют результатам переписей населения, а также подтверждают результаты опроса «Рождаемость и семья в Швеции» (Swedish Fertility and Family Survey), проведенного в 1992 г. (таблица 1). Авторы приходят к выводу, что информация, полученная на основе регистров, достаточно достоверна для того, чтобы применяться в анализе места проживания родителей при рождении ребенка. Разница в оценках может объясняться самим подходом к определению сожительства, а также изменением выборки ${ }^{4}$.

\footnotetext{
${ }^{2}$ Level of Living Survey.

${ }^{3}$ Multi-Generation Register.

${ }^{4}$ В 1987-1992 гг. велся учет только по женщинам - как рожденным на территории Швеции, так и мигрантам (при условии того, что рождение ребенка произошло на территории Швеции), а в 1990-1999 гг. учет велся только по коренным жителям - как по женщинам, так и по мужчинам.
} 
Таким образом, регистры населения представляют собой источник актуальной информации о брачном статусе жителей, однако достоверность получаемых данных следует дополнительно проверять с помощью выборочных исследований. Еще более сложным является проведение межстрановых сравнений распространенности сожительств на основе данных регистров населения, так как различия в определении самого термина «сожительство» и факт включения или не включения в выборку мигрантов и временно проживающих лиц может существенно влиять на результаты исследований.

\section{УЧЕТ ПАРТНЕРСКИХ СОЮЗОВ В РЕГИСТРАХ НАСЕЛЕНИЯ}

Методы учета лиц, проживающих в незарегистрированном браке, варьируются от страны к стране, различается и сам подход к определению незарегистрированного брака. Это связано с тем, что у него зачастую нет четкой даты начала, как нет и четкой даты окончания, партнеры могут съезжаться и разъезжаться, между ними не всегда существует согласие относительно текущего статуса их отношений [Исупова 2013]. Наиболее широкий список разновидностей незарегистрированных браков представлен на сайте правительства Нидерландов ${ }^{5}$. Выделяются следующие типы незарегистрированных браков в зависимости от возможностей их учета:

- сожительство без регистрации брака (cohabitation);

- зарегистрированное партнерство (registered partnership);

- соглашение о сожительстве (cohabitation agreement).

Для начала рассмотрим те альтернативы традиционному браку, которые регистрируются самими гражданами и тем самым позволяют вести учет истории этих отношений. К ним относятся зарегистрированное партнерство и соглашение о сожительстве, в последние годы приобретающие популярность ${ }^{6}$. Регистрация сожительства является взаимовыгодной сделкой для государства и его граждан: первое получает актуальные данные для статистических служб непосредственно от самих жителей, вторые получают практически те же права, что и лица, состоящие в зарегистрированном браке. Немаловажное значение при этом играют налоговые льготы, более выгодные условия для страхования жизни и здоровья, а также пенсионные выплаты, стимулирующие граждан предоставлять своевременную информацию о своих партнерских отношениях в административные органы ${ }^{7}$. Зарегистрированное партнерство (registered partnership) между партнерами разного пола является легитимным в Норвегии, Нидерландах, Бельгии, Франции, Люксембурге, Эстонии и Исландии.

\footnotetext{
${ }^{5}$ См.: https://www.government.nl/topics/family-law/contents/marriage-registered-partnership-and-cohabitationagreements.

${ }^{6}$ Вопрос, почему многие современные пары предпочитают регистрировать совместное проживание, но не вступать в официальный брак, является предметом отдельного изучения и не затрагивается в настоящей статье.

${ }^{7}$ К сожалению, тема влияния введения мотивирующих механизмов для регистрации партнерства в научной литературе пока не рассматривалась, поэтому мы не можем судить, в какой степени правовые аспекты являются предпосылкой регистрации сожительства.
} 
Норвегия узаконила зарегистрированное партнерство в 1993 г., предоставив парам, вступившим в него, те же права, что и парам, официально заключившим брак.

В Нидерландах впервые начали регистрировать партнерства в 1998 г., и сегодня они практически приравниваются к зарегистрированному браку: партнеры имеют почти одинаковые права, отличия в основном касаются детей. Если в случае зарегистрированного брака мужчина автоматически становится законным отцом ребенка, то в случае зарегистрированных партнерств мужчина, чтобы приобрести статус отца, должен официально признать ребенка. Партнерства регистрируются в гражданском регистре рождений, смерти, браков и зарегистрированных партнерств, а также в муниципальной базе персональных данных. Перед регистрацией партнерства пара должна зарегистрировать свое намерение путем подачи «уведомления о намерениях» в местный муниципалитет по месту проживания одного из партнеров.

Институт зарегистрированных партнерств также распространен и в Бельгии, где он носит название «официального сожительства» (legal cohabitation). Согласно закону от 23 ноября 1998 г., официальное сожительство приравнивается к заключению зарегистрированного брака и фиксируется в регистрах населения. Факты регистрации сожительства первоначально собираются на уровне местных муниципальных регистров населения и далее интегрируются в национальном регистре населения.

Во Франции права лиц, состоящих в зарегистрированном партнерстве, практически уравнены с правами лиц, состоящих в зарегистрированном браке. Зарегистрированное партнерство (Civilian pact of solidarity, pp. Pacte civil de solidarité = PACS) было официально признано во Франции в 1999 г. и с тех пор приобрело большую популярность. Например, в 2005 г. наряду с 271 тыс. официальных браков было зарегистрировано практически 60 тыс. партнерств [Sobotka, Toulemon 2008:103].

В Люксембурге партнерское сожительство (PACS), легитимированное в 2004 г., регистрируется в гражданском регистре в муниципалитете по месту жительства партнеров. Здесь также создан гражданский индекс (civil index) - уникальный всеобщий регистр, в котором регистрируются как национальные, как и иностранные партнерства, признаваемые на территории Люксембурга.

В Исландии также существует регистрация сожительства (registered cohabitation), однако она является лишь правовым статусом лиц, проживающих совместно, но не семейным положением. Поэтому в регистре населения Исландии лица, состоящие в зарегистрированном сожительстве, учитываются как «не состоящие в браке», «вдовы/вдовцы», «разведенные», но не как «состоящие в браке». Лица, состоящие в зарегистрированном партнерстве, не несут ответственности за финансовое состояние партнера и не имеют прав наследования, если то не указано в завещании. Привилегии пары, зарегистрировавшие партнерство, получают лишь в отношении налоговых сборов, прав на рынке труда, а также в отношении гражданских услуг, предоставляемых местными муниципалитетами.

В Эстонии зарегистрированные партнерства устанавливают правила, по которым члены партнерства обязаны поддерживать друг друга, и принимают обязанности, 
связанные с сожительством. В Испании партнерское сожительство регистрируется лишь в региональных регистрационных офисах, центрального регистра не существует.

Одним из главных правовых вопросов сожительства является право наследования. В Норвегии и Нидерландах лица, зарегистрировавшие партнерство, получают те же права наследования и выплачивают налог на наследование в том же размере, что и законные супруги. Однако это распространяется отнюдь не на все страны: в Бельгии партнер получает лишь вещное право (law of property) на недвижимость, в котором он проживал с умершим партнером, а во Франции и Люксембурге партнер может рассчитывать на получение наследства лишь в случае наличия завещания.

Правовые различия между заключением официального брака и регистрацией партнерства в основном касаются родительских прав, которые получают лишь лица, состоящие в браке. Получить родительские права можно путем регистрации (повторной) рождения ребенка совместно с его матерью, вступив в брак с матерью ребенка, заключив родительское соглашение с матерью и зарегистрировав его через суд, а также став опекуном ребенка в случае смерти его матери. С другой стороны, в большинстве случаев факт регистрации брака не имеет значения для получения ребенком наследства: он получает его как от родителей, состоящих в браке, так и от зарегистрировавших партнерство. Альтернативной формой регистрации партнерства является соглашение о сожительстве (cohabitation agreement) - письменное соглашение, устанавливающее определенный порядок совместного проживания партнеров, в большинстве случаев это нотариально заверенный договор. В Нидерландах он служит основанием для получения пенсий по партнерским схемам, а также дополнительных льгот. В Бельгии данный документ, достаточно широко распространенный в стране, носит название «Контракт о сожительстве» (The Cohabitation Contract), заключать его могут только жители Бельгии. Декларация включает следующие пункты: дата подписания декларации, имена, даты рождения, места рождения, адрес проживания, а также подписи сторон, заключающих соглашение. Лица, заключившие подобный контракт, разделяют ответственность за общие расходы, а также извлекают общую выгоду от любых активов, приобретённых во время сожительства. Партнерское сожительство ${ }^{8}$ (cohabiting partnership), греческий аналог рассмотренных выше партнерств, заключается через оформление нотариального акта. Факты партнерских сожительств регистрируются в местных офисах регистрации, которые связаны с центральной информационной системой регистрации в Министерстве внутренних дел.

Введение регистрации партнерств и сожительств непосредственно самими гражданами упрощает процедуру учета подобных союзов. Несколько сложнее строится учет пар, не регистрирующих партнерство, он обычно проводится с помощью определения места жительства граждан. Проблемным местом при учете никак не зарегистрированных союзов является тот факт, что в большинстве случаев регистрация идет лишь по домам, а не отдельным апартаментам. В результате учесть факт совместного проживания таких пар можно лишь после рождения у них детей, так как это событие фиксируется в регистрах и позволяет построить связь между партнерами.

\footnotetext{
${ }^{8}$ Greek law digest. URL: http://www.greeklawdigest.gr/topics/basic-aspects-of-civil-law/item/25-family-law WWW.DEMREVIEW.HSE.RU
} 


\section{Учет партнерств по детям}

Учет сожительствующих и имеющих детей пар несколько проще, чем учет пар без детей, так как при рождении ребенка указываются идентификационные номера их биологических родителей.

Наиболее эффективная система учета незарегистрированных браков на основе данных о рождении детей разработана в Швеции. Швеция является второй страной в мире (после Исландии) по доле детей, рожденных вне зарегистрированного брака [Thomson 2005]. В 2014 г. 44,5\% детей в возрасте до одного года проживали в семьях, состоящих из партнеров, проживающих совместно без регистрации брака [Statistics of Sweden 2014]. Учет детей, рожденных вне зарегистрированного брака, строится на использовании трех основных ресурсов данных: регистра поколений, общего регистра населения, а также данных переписей. Регистр поколений содержит данные о родственных связях нескольких поколений, включая связи детей с их биологическими родителями, даже в случае, если они не состояли в браке. Вопросы, включенные в регистр, различаются для лиц женского и мужского пола: регистр для женского населения включает информацию о дате рождения всех детей, их идентификационные номера, номера супругов, а также номера партнеров, от которых были рождены дети до заключения брака. Регистр для мужского населения включает ту же информацию, кроме данных о детях: связь мужчин с их детьми прослеживаются через идентификационные номера женщин. В карточки детей заносится информация о дате их рождения, номера их биологических отца и матери. Эти данные позволяют вычислить, были ли дети рождены после или до заключения брака и был ли заключен брак с их биологическим отцом во втором случае. В общем регистре населения указывается, по какому адресу прописаны граждане на конец каждого календарного года и какой жилищной собственностью они обладают. Наконец, данные переписей позволяют построить связи между жилищными единицами и каждым конкретным гражданином страны на момент проведения переписи, что дает возможность определить, проживает пара совместно или раздельно, а также являются дополнительным инструментом проверки достоверности данных регистров.

Несколько иной подход к учету детей, рожденных вне зарегистрированного брака, в Норвегии, где помимо личных идентификационных номеров граждан введены идентификационные номера семей (по факту регистрации брака), а также сожительствующих пар, имеющих как минимум одного общего ребенка (по факту проживания по общему адресу). Это позволяет вести учет проживающих совместно пар, имеющих детей, но не зарегистрировавших брак или партнерство.

\section{Учет пар, проживающих совместно без какой-либо регистрации}

Самая развитая и эффективная система учета сожительствующих пар создана в Финляндии на основе регистра населения Palapeli. Регистр Palapeli включает личные идентификационные номера граждан, через которые также можно проследить занятость граждан на рынке труда, их уровень образования и доходов. Данная система учета была введена в Финляндии в 1987 г. Проведено большое количество исследовательских работ, посвященных институту сожительства, основанных именно на финском регистре 
населения.

С 2005 г. введение уникальных адресов для всех помещений в Норвегии также позволило вести учет пар, проживающих совместно и не имеющих общих детей. Еще одной страной, где регистрация населения происходит по конкретным апартаментам, являются Нидерланды: как только два человека начинают жить по одному и тому же адресу, они обязаны заявить об этом в административную службу, после чего они автоматически учитываются в регистре как отдельное домохозяйство. Информация о месте проживания граждан находится в муниципальной базе персональных данных. Дания является одной из стран, где широко распространены нерегистрируемые браки и создана эффективная система их учета. Данные из Центрального регистра населения на ежедневной основе поступают в Статистическую службу, где учет населения проводится в трех измерениях: домохозяйства, семьи, индивидуальных лиц. В семейном регистре семьи подразделяются на две категории: состоящие из одного человека и состоящие из пары с детьми или без детей. В последнем случае осуществляется учет следующих видов пар, проживающих совместно:

- пара, состоящая в зарегистрированном браке;

- зарегистрированное партнерство;

- пара, проживающая совместно: два человека разного пола, проживающие по одному адресу, не имеющие общих детей, разница в возрасте которых составляет не более 15 лет.

Пара получает уникальный идентификационный номер семьи, когда партнеры начинают проживать по общему адресу. При этом номер семьи не изменяется при изменении типа семьи: например, при заключении партнерами официального брака или при разводе, если бывшие супруги продолжают проживать совместно.

В целом можно сказать, что развитие института регистрации сожительства или партнерства, которое только начинается в европейских странах, является эффективным комплементарным инструментом ведения статистического учета населения. Самостоятельная регистрация партнерства повышается актуальность данных и позволяет существенно снижать издержки на ведение учета брачного состояния населения.

\section{ИССЛЕДОВАНИЯ ПАРТНЕРСКИХ СОЮЗОВ НА ОСНОВЕ ДАННЫХ РЕГИСТРОВ НАСЕЛЕНИЯ}

Большинство научных работ на основе регистров населения используют данные скандинавских стран. Многие исследования выполнены и на основе данных регистров Нидерландов, но в большинстве своем они посвящены пространственным факторам, влияющим на распространенность сожительств, а также на вероятность вступления в подобный союз. На основе данных датского регистра населения было сделано лишь несколько работ - как отмечалось ранее, он обладает специфической категоризацией, затрудняющей международные сравнения. В целом все исследования можно подразделить на несколько тематических блоков: 
- факторы, влияющие на длительность взаимоотношений;

- факторы, влияющие на вероятность вступления в незарегистрированный союз;

- влияние распространенности незарегистрированных браков на рождаемость;

- влияние брачного статуса на продолжительность жизни;

- факторы перехода от сожительства к зарегистрированному браку;

- достоверность данных и прогнозы.

В каждой работе так или иначе даются общие оценки распространенности незарегистрированных браков и тенденций трансформации института семьи с учетом региональной специфики, но можно отметить работы, посвященные исключительно этой теме. На основе данных финского регистра в 2007 г. было проведено обследование сожительствующих пар [Pitkänen, Jalovaara 2007], по результатам которого было выявлено, что доля лиц, состоящих в незарегистрированном браке в период с 1970 по 2005 г. увеличилась с 2,5\% практически до $25 \%$.

В 2013 г. было проведено международное исследование домохозяйств на основе данных жилищных регистров Дании и Финляндии с 1980 г. [Christiansen, Keilman 2013]. Ha базе информации о месте проживания граждан, их семейного положения и наличия детей авторы статьи строят прогноз того, как будут выглядеть домохозяйства через 30 лет, и предсказывают увеличение одиночных домохозяйств, снижение доли домохозяйств, состоящих из пар в зарегистрированном браке, и постоянство доли домохозяйств, состоящих из пар в незарегистрированном браке.

\section{Исследования факторов вступления в незарегистрированный союз}

Исследования, посвященные факторам, влияющим на вероятность вступления в незарегистрированный союз, можно разделить на две категории: анализ социальноэкономических параметров, а также влияние места проживания партнеров на вероятность их вступления в партнерские отношения.

В первой категории следует отметить работу, выполненную на основе данных финского регистра населения [Jalovaara 2012], согласно результатам которой такие факторы, как высокий уровень образования, занятость и высокий уровень дохода лиц, вступающих в союз, способствуют формированию незарегистрированных союзов, при этом не выявлены какие-либо существенные гендерные различия.

Ко второй категории относятся работы голландских исследователей, в первую очередь К. Хаандрикмана, С.Хармсена и Л. ван Винсена, которые исследовали влияние расстояния между местом жительства партнеров в LAT-союзе ${ }^{9}$ на вероятность начала их совместного проживания [Haandrikman et al. 2008]. Авторы статьи приходят к выводу, что голландцы склонны выбирать партнеров, проживающих недалеко от их места жительства (половина находит себе партнера в пределах 6 км от своего места жительства), при этом данная тенденция лишь усиливается с увеличением возраста партнеров. С другой стороны,

\footnotetext{
${ }^{9}$ LAT (Living apart together) - союзы, члены которого находятся в близких романтических отношениях, но проживают раздельно (в русском языке они описываются словом «встречаются», в научной литературе можно встретить термин «гостевое партнерство»).
} 
лица, проживающие с родителями, а также те, кто сам является родителем-одиночкой, живут значительно ближе к своим будущим партнерам, нежели остальные.

В следующей работе тех же авторов проводится анализ влияния близости места проживания индивидов друг от друга на вероятность вступления в официальный или неофициальный союз [Наandrikman et al. 2011]. В ней показано, что с увеличением уровня образования и дохода увеличивается среднее расстояние между местом проживания партнеров до переезда по общему адресу, и делается вывод о том, что чем выше уровень развития общества, тем в меньшей степени расстояние влияет на выбор партнера.

К редким работам, основанным на данных бельгийского регистра населения, относится исследование социологов С. Ванасше, М. Кориджина и К. Матиуса [Vanassche, Corijn, Matthijs 2015], в котором анализируется, как скоро лица, пережившие развод, вновь начинают проживать вместе с новыми партнерами и через какой срок они регистрируют новые браки. Выбрав из бельгийского регистра населения лиц, переживших развод менее 7 лет назад, авторы брали интервью по возможности у обоих бывших супругов. Учет новых партнерских отношений проводился лишь в том случае, если они длились по меньшей мере 3 месяца. Согласно результатам исследования, треть лиц, переживших развод, в течение первых 7 лет после него остаются одинокими, при этом среди вступивших в новые отношения преобладают проживающие в незарегистрированных браках (хотя с увеличением времени, прошедшего с момента развода, доля вступивших в новый зарегистрированный брак растет).

Д. Холланд [Holland 2013] на основе данных административных регистров Швеции приходит к выводу, что до сих пор в Швеции самыми распространенными являются браки, заключаемые до зачатия ребенка, а доля браков, заключаемых после зачатия или спустя 12 месяцев после первого рождения, снижается. Это говорит о том, что брак как мера «легитимизации» рождений детей теряет свое былое значение. Растет доля тех, кто заключает браки уже после рождения двух и более детей.

\section{Исследования длительности партнерских отношений}

Факторы, влияющие на длительность партнерских отношений и вероятность распада союза, находятся в центре внимания исследователей, работающих с регистрами населения.

Одним из первых обратился к теме незарегистрированных браков норвежский социолог О. Кравдал, который, используя данные регистра населения Норвегии, пришел к выводу, что женщины, родившие до заключения брака, имеют более высокую вероятность распада их первого союза, даже если с отцом этих детей брак был впоследствии заключен [Kravdal 1988]. В дальнейшем в статье Т.Х. Лингстада данные регистра населения Норвегии были проанализированы совместно с результатами переписи 1980 г. [Lyngstad 2004]. Результаты исследования позволили сделать вывод о том, что вероятность развода пары, чей ребенок был рожден до регистрации брака, снизилась по сравнению с 1988 г., когда было опубликована работа О. Кравдала.

В статье шведского социолога Г. Лиу [Liu 2002] также доказывается, что в семьях, в которых есть дети, рожденные до заключения официального брака, вероятность развода выше, чем в семьях, где таких детей нет. Более того, если у женщины есть дети от другого 
партнера, такие семьи подвержены еще большему риску развода. При этом наличие детей у мужчины от предыдущей партнерши влияет на прочность брака в гораздо меньшей степени.

В статье М. Сварера на основе данных датского регистра рынка труда делается вывод о том, что пары, которые проживают совместно до заключения официального брака, имеют меньший риск развода, чем пары, которые не проживали вместе [Svarer 2004]. При этом чем дольше период, в течение которого пара живет без регистрации брака, тем меньше вероятность развода после его заключения. Данные выводы противоречат большей части исследований на эту тему, проводившихся в других странах: Blanc (1985 г.) - Норвегия; Bennett, Blanc, Bloom (1988 г.), Trussell, Trussell (1992 г.), Hoem (1992 г.) - Швеция. Это, согласно мнению Сварера, свидетельствует о специфике отношения датского населения к сожительству. В результате анализа влияния урбанизации на склонность к вступлению в незарегистрированный брак был сделан вывод о том, что лица, проживающие вдали от метрополии Копенгагена, чаще проживают совместно с партнером до заключения брака, чем жители Копенгагена.

В 2007 г. на базе регистров населения Нидерландов было выявлено, что вероятность распада незарегистрированного союза уменьшается при увеличении уровня дохода домохозяйства и увеличивается при росте доли заработка женщины в общем доходе домохозяйства [Kalmijn, Loeve, Manting 2007]. Для пар, проживающих совместно без регистрации брака, равенство ролей мужчины и женщины уменьшает вероятность распада союза.

Исследование 2013 г., построенное на данных финского регистра населения, выявило, что низкий уровень образования, безработица (особенно среди мужчин) и низкий уровень дохода повышают вероятность распада как зарегистрированных, так и незарегистрированных браков [Jalovaara 2013]. При этом влияние данных факторов оказывается сильнее для пар, состоящих в зарегистрированном браке. В статье утверждается, что экономическая теория семьи Г. Бекера всё в меньшей степени отражает современную действительность: стабильность браку, и в особенности незарегистрированным союзам, приносит скорее социально-экономическое равенство партнеров, нежели их специализация (мужчина - кормилец, женщина отвечает за ведение хозяйства). Тем не менее, если вклад женщины в общий доход домохозяйства выше половины, это повышает риск распада союзов (как зарегистрированных, так и незарегистрированных). Согласно результатам исследования, пары, начинающие жить совместно без регистрации брака, распадаются в течение 10 лет более чем в $50 \%$ случаев, а заключают впоследствии официальный брак менее 40\%. В продолжение этой работы в 2014 г. вышло исследование, демонстрирующее, что разница в уровне образования лиц, проживающих совместно без регистрации брака, играет большую роль в вероятности распада союза: он тем прочнее, чем выше уровень образования обоих партнеров [Mäenpää, Jalovaara 2014]. 


\section{Исследования перехода от сожительства к зарегистрированному} браку

В работе А-3. Дювандер база данных шведского регистра населения была дополнена результатами опроса «Семья в Швеции» (Swedish Family Survey), в выборку исследования попали женщины, проживающие совместно с партнером без регистрации брака и никогда ранее не состоявшие в браке [Duvander 1999]. У женщин, которые были моложе своего партнера на 5 лет и более, вероятность вступления в брак оказалась вдвое выше, чем у тех, чья разница в возрасте была менее существенной. Также вероятность вступления в брак у женщин, проживающих во втором или третьем незарегистрированном союзе, была выше, чем у женщин, проживающих в подобном союзе впервые. В статье отмечается, что вероятность вступления в брак была выше у женщин, партнер которых имел высшее образование, а также женщин из семей с обоими родителями (родными либо приемными). Интересен факт, что наличие соглашения о сожительстве (cohabitation agreement) никак не влияло на вероятность заключения брака.

В работе Е. Маенпя [Mäenpää 2009], основанной на данных выборки из Palapeli (финского регистра населения), также рассматриваются социально-экономические факторы вступления пар, проживающих совместно в неофициальном союзе, в зарегистрированный брак. Автор приходит к выводу, что наибольшая вероятность регистрации брака наблюдается в парах с высшим образованием, а наименьшая - в парах, где мужчина имел низкий уровень образования, а женщина - высокий. Также пары были в меньшей степени склонны регистрировать свой брак, если мужчина оказывался без работы на срок от 6 месяцев, а женщина не имела работы вообще. Автор отмечает, что вероятность заключения брака увеличивается с ростом уровня дохода, за одним исключением - если уровень дохода женщины выше, чем мужчины.

Чуть позже в соавторстве с М. Яловаара Е. Маенпя [Mäenpää, Jalovaara 2013] доказала, что фактор гомогенности социально-экономических характеристик членов союза не является существенным для регистрации парой своих отношений. Исключение составляют лишь жители сельской местности, а также лица, получившие только базовое общее образование: они более склонны регистрировать брак, если социальный статус партнера тот же, что и у них.

Результаты приведенных выше исследований можно свести в единую общую таблицу (таблица 2), из которой видно, что такие социально-экономические факторы, как наличие высшего образования, занятость и уровень дохода, увеличивают вероятность как сожительства, так и последующего вступления в зарегистрированный брак. Напротив, рождение детей до заключения официального брака и время, проведенное в неофициальном союзе, как правило, увеличивают шансы распада союза. Наконец, размер населенного пункта и расстояние между местом проживания потенциальных партнеров снижают вероятность вступления лиц в незарегистрированный брак. 
Таблица 2. Факторы влияния на формирование и распад незарегистрированных союзов и переход к зарегистрированному браку

\begin{tabular}{|c|c|c|c|}
\hline & $\begin{array}{c}\text { Вступление в } \\
\text { незарегистрированный } \\
\text { сою3 } \\
\end{array}$ & $\begin{array}{c}\text { Переход к } \\
\text { зарегистрированному } \\
\text { браку } \\
\end{array}$ & $\begin{array}{c}\text { Распад } \\
\text { незарегистрированного } \\
\text { союза } \\
\end{array}$ \\
\hline $\begin{array}{l}\text { Наличие высшего } \\
\text { образования }\end{array}$ & Положительное влияние & $\begin{array}{l}\text { Положительное } \\
\text { влияние }\end{array}$ & $\begin{array}{l}\text { Отрицательное } \\
\text { влияние }\end{array}$ \\
\hline Занятость & Положительное влияние & $\begin{array}{l}\text { Положительное } \\
\text { влияние }\end{array}$ & $\begin{array}{l}\text { Отрицательное } \\
\text { влияние }\end{array}$ \\
\hline Уровень дохода & Положительное влияние & $\begin{array}{l}\text { Положительное } \\
\text { влияние }\end{array}$ & $\begin{array}{l}\text { Отрицательное } \\
\text { влияние }\end{array}$ \\
\hline $\begin{array}{l}\text { Время, прошедшее со } \\
\text { времени развода }\end{array}$ & Положительное влияние & & \\
\hline $\begin{array}{l}\text { Наличие общих детей до } \\
\text { заключения брака }\end{array}$ & & $\begin{array}{l}\text { Теряет свое былое } \\
\text { значение }\end{array}$ & $\begin{array}{l}\text { Положительное } \\
\text { влияние по сравнению } \\
\text { с женщинами, } \\
\text { родившими в браке }\end{array}$ \\
\hline $\begin{array}{l}\text { Гомогенность социально- } \\
\text { экономических } \\
\text { характеристик }\end{array}$ & & $\begin{array}{l}\text { Не является } \\
\text { существенным } \\
\text { фактором для } \\
\text { регистрации парой } \\
\text { своих отношений }\end{array}$ & $\begin{array}{l}\text { Отрицательное } \\
\text { влияние }\end{array}$ \\
\hline $\begin{array}{l}\text { Время, прожитое в } \\
\text { незарегистрированном союзе }\end{array}$ & & & $\begin{array}{l}\text { Положительное } \\
\text { влияние (кроме Дании) }\end{array}$ \\
\hline $\begin{array}{l}\text { Размер населенного пункта } \\
\text { Расстояние между } \\
\text { партнерами }\end{array}$ & $\begin{array}{l}\text { Отрицательное влияние } \\
\text { Отрицательное влияние }\end{array}$ & & \\
\hline
\end{tabular}

Помимо исследований непосредственно партнерских отношений, немало работ посвящено влиянию статуса союза на рождаемость и смертность. Большинство исследователей сходится во мнении, что пары, состоящие в зарегистрированном браке, более склонны иметь детей, чем проживающие совместно без его регистрации [Rønsen 2004; Hoem, Jalovaara, Mureşan 2013; Dribe, Stanfors 2009]. В ряде работ отмечается, что продолжительность жизни лиц, проживающих совместно без заключения брака, ниже, чем у состоящих в зарегистрированном браке, но несколько выше, чем у проживающих одиноко [Martikainen et al. 2005; Koskinen et al. 2007]. В отечественной литературе тема влияния брачного статуса на смертность была затронута в работе [Школьников, Андреев, Малева 2000], однако незарегистрированные браки в ней, к сожалению, не рассматриваются. Отдельно стоит выделить работу датского исследователя С. Дрефаля [Drefahl 2012], который рассматривает смертность в разрезе брачного статуса и социальных параметров. Автор отмечает гендерные различия в отношении смертности: среди лиц, состоящих в зарегистрированном браке, она находится на самом низком уровне (для обоих полов), а наиболее высокие значения она приобретает для одиноких мужчин и для женщин, состоящих в незарегистрированном браке. Также автор отмечает, что социальный статус является значимым фактором смертности лишь для мужчин, в то время как для женщин он не играет большой роли. Среди мужчин со средним уровнем образования уровень смертности не зависит от статуса союза. При этом среди тех, кто состоит в зарегистрированном браке, смертность наблюдается у лиц с низким уровнем образования, а среди сожительствующих - с высоким. У женщин наблюдается существенно более высокий уровень смертности среди состоящих в незарегистрированном браке и с низким уровнем образования; у женщин с высоким уровнем образования разница в уровне 
смертности в зависимости от факта регистрации брака или ее отсутствия практически не наблюдается.

\section{ЗАКЛЮЧЕНИЕ}

Регистры населения предоставляют богатые возможности для исследования демографического поведения населения, и матримониальное поведение не является исключением. Данные регистров успешно используются для оценок распространенности незарегистрированных брачных союзов, их длительности, факторов формирования и прекращения, а также влияния пребывания в том или ином типе партнерства на репродуктивное поведение и продолжительность жизни. Основными преимуществами использования регистров являются покрытие всего населения региона, низкие издержки на извлечение данных, актуальность данных и возможность проведения лонгитюдного анализа брачно-партнерских отношений.

Вместе с тем регистры населения, как и любой другой реальный источник информации, имеют ряд недостатков и ограничений. Оценка незарегистрированных браков с помощью регистров строится на основе информации об адресе проживания граждан, однако в ряде стран до сих пор идентифицировать сожительствующие пары возможно лишь после рождения у них общего ребенка. Еще одним фактором искажения данных является временной лаг: зачастую пары регистрируют новое место жительства лишь спустя некоторое время после переезда, что несколько занижает реальную оценку распространенности сожительств. Уязвимым местом регистров с точки зрения проведения международных исследований являются межстрановые различия учета населения, например критерии учета иностранных граждан.

В настоящее время страны, чьи статистические системы базируются на регистрах, двигаются дальше по пути создания массивов демографических данных. Ускоряющаяся оцифровка архивных документов вкупе с современными методами сбора и хранения информации в электронном виде позволяют создавать крупные базы связанных данных. Связываются раунды переписей населения (например, к переписи 1880 г. в США были привязаны 6 последующих раундов ${ }^{10}$ ), переписей и регистров (например, проект CeLSIUS $^{11}$ ), на основе регистров формируются выборки обследований (например, для исследования жизненного пути близнецов ${ }^{12}$ ), активно развиваются базы социальнодемографических данных, к которым привязываются индивидуальные медицинские сведения ${ }^{13}$. В настоящий момент подобные массивы носят разрозненный характер (в одних только Нидерландах вокруг Исторической выборки населения 1812-1922 гг. рождения

\footnotetext{
${ }^{10}$ См. описание методики: https://www.nappdata.org/napp/linked_samples.shtml. Сделано три раздельных массива: мужчин, женщин и супругов.

${ }^{11}$ См.: http://celsius.lshtm.ac.uk/modules/events/ev010000.html. Построена выборка 1\% населения Англии и Уэльса, наблюдение за которой ведется с переписи 1971 г.

${ }^{12}$ См.: http://www.tweelingenregister.org/en/information/. На регулярной основе в семьи близнецов отправляются вопросники по широкому перечню социально-демографических тем.

${ }^{13}$ Например, проект http://www.ru.nl/genesandgerms/ сейчас в стадии разработки, внесены данные о вступлениях в брак в период с 1812 по 1922 г., ряд будет продлен до 2015 г.
} 
(HSN) создано несколько подобных проектов ${ }^{14}$ ), однако набирает силу тенденция к объединению данных разных регионов и источников. В дальнейшем подобные базы, в основе которых лежат регистры населения, откроют многообещающие горизонты для комплексных исследований социально-демографического поведения населения, в том числе исследований партнерских и брачных союзов. Успешное применение систем аккумуляции информации из разных унифицированных источников в ряде европейских стран позволяет говорить о ее высоком потенциале, который можно было бы использовать и в России.

\section{ЛИТЕРАТУРА}

Андриченко Л.В., М.А. Мещерякова (2012). Информационные регистры как эффективное средство сбора и мониторинга данных о населении // Журнал российского права. 8: 1640 .

Бахметова Г.Ш., А.А. Исупов (1999). Регистр населения как система демографического учета // Вопросы статистики. 5: 33-39.

Иванова Е.И. (2012). Современный текущий статистический учет естественного движения населения: возможности его применения для социально-демографического анализа // Вестник РГГУ. 2: 98-112.

Исупова О.Г. (2013). Мы просто живем вместе // Демоскоп Weekly. №565-566. URL: http://demoscope.ru/weekly/2013/0565/tema01.php (дата обращения: 22.04.2016).

Клупт М.А., О.Н. Никифоров (2010). Альтернативные методы проведения переписей населения: применимы ли они в России? // Вопросы статистики. 9: 3-8.

Неравенство и смертность в России (2000) / Под ред. В. Школьникова, Е. Андреева и Т. Малевой. М.: Московский Центр Карнеги. 107 с.

Пьянкова А.И. (2014). Традиционный и альтернативные методы проведения переписей населения: дис. ... канд. социол. наук. Федеральное государственное автономное образовательное учреждение высшего профессионального образования «Национальный исследовательский университет «Высшая школа экономики», Москва.

Carlson M., I. Garfinkel, S. McLanahan, R. Mincy, W. Primus (2004). The effects of welfare and child support policies on union formation // Population research and policy review. 23: 513542 .

Christiansen S.G., N. Keilman (2013). Probabilistic household forecasts based on register data the case of Denmark and Finland // Demographic research. 28(43): 1263-1302.

Drefahl S. (2012). Do the married really live longer? The role of cohabitation and socioeconomic status // Journal of marriage and family. 74: $462-475$.

Dribe M., M. Stanfors (2009). Does parenthood strengthen a traditional household division of labor? Evidence from Sweden // Journal of marriage and family. 71(1): 33-45.

Duvander A-Z. E. (1999). The transition from cohabitation to marriage. A longitude study of the propensity to marry in Sweden in the early 1990s // Journal of family issues. 20 (5): 698717.

${ }^{14}$ CM.: https://socialhistory.org/en/hsn/hsn-projects. 
Haandrikman K., C. Harmsen, L.J.G. van Wissen, I. Hutter (2008). Geography matters: patterns of spatial homogamy in the Netherlands // Population, space and place. 14: 387-405.

Haandrikman K., L.J.G. van Wissen, C. Harmsen (2011). Explaining spatial homogamy. Compositional, spatial and regional cultural determinants of regional patterns of spatial homogamy in the Netherlands // Appl. spatial analysis. 4: 75-93.

Hoem J.M., M. Jalovaara, C. Mureşan (2013). Recent fertility patterns of Finnish women by union status: a descriptive account // Demographic research. 28(14): 409-420.

Holland J.A. (2013). Love, marriage, then the baby carriage? Marriage timing and childbearing in Sweden // Demographic research. 29(11): 275-306.

Jalovaara M. (2012). Socio-economic resources and first-union formation in Finland, cohorts born 1969-81// Population studies. 66(1): 69-85.

Jalovaara M. (2013). Socioeconomic resources and the dissolution of cohabitations and marriages // European journal of population. 29(2): 167-193.

Kalmijn M., A. Loeve, D. Manting (2007). Income dynamics in couples and the dissolution of marriage and cohabitation // Demography. 44(1): 159-179.

Keilman N., H. Brunborg (1995). Probabilistic household forecasts based on register data- the case of Denmark and Finland // Demographic research. 28(43): 1263-1302.

Koskinen S., K. Joutsenniemi, T. Martelin, P. Martikainen (2007). Mortality differences according to living arrangements // International journal of epidemiology. 36:1255-1264.

Kravdal Ø. (1988). The impact of first-birth timing on divorce: New evidence from a longitudinal analysis based on the central population register of Norway // European journal of population. 4(3): 247-269.

Liu G. (2002). How premarital children and childbearing in current marriage influence divorce of Swedish women in their first marriages // Demographic research. 7(10): 389-406.

Lyngstad T.H. (2004). The impact of parents' and spouses' education on divorce rates in Norway // Demographic research. 10(5): 122-142.

Mäenpää E. (2009). Cohabiting partners' socioeconomic characteristics and the transition to marriage in Finland // Finnish yearbook of population research: 63-77.

Mäenpää E., M. Jalovaara (2013). The effects of homogamy in socio-economic background and education on the transition from cohabitation to marriage // Actasociologica. 56(3): 247-263.

Mäenpää E., M. Jalovaara (2014). Homogamy in socio-economic background and education, and the dissolution of cohabiting unions // Demographic research. 30(65): 1769-1792.

Martikainen P., T. Martelin, E. Nihtilä, K. Majamaa, S. Koskinen (2005). Differences in mortality by marital status in Finland from 1976 to 2000: analyses of changes in maritalstatus distributions, socio-demographic and household composition, and cause of death // Population studies. 59(1): 99-116.

Perelli-Harris B., N. Sánchez Gassen (2012). How similar are cohabitation and marriage? Legal approaches to cohabitation across Western Europe // Population and development review. 38(3): 435-467.

Pitkänen K., M. Jalovaara (2007). Perheet ja perheenmuodostus [Family formation]. 2nd renewed edition: $115-168$.

Poulain M., A. Herm (2013). Central population registers as a source of demographic statistics in Europe // Population-E. 68(2): 183-212. 
Rønsen M. (2004). Fertility and public policies - evidence from Norway and Finland // Demographic research. 10(6): 143-170.

Sobotka T., L. Toulemon (2008). Overview chapter 4: Changing family and partnership behaviour: common trends and persistent diversity across Europe // Demographic research. 19(6): 85-138.

Svarer M. (2004). Is your love in vain? Another look at premarital cohabitation and divorce // Journal of human resources. 39(2): 523-535.

Thomson E. (2005). Partnership and parenthood: Connections between cohabitation, marriage and childbearing // Booth A., Crouter N. The new population problem: why families in developed countries are shrinking and what it means. Mahwah, NJ: Lawrence Erlbaum Associate: $129-149$.

Thomson E., H. Eriksson (2013). Register-based estimates of parents' co-residence in Sweden, 1969-2007 // Demographic research. 29(42): 1153-1186.

Statistics of Sweden (2014). URL: http://www.statistikdatabasen.scb.se/ (дата обращения: 23.05.2016).

Vanassche S., M. Corijn, K. Matthijs (2015). Post-divorce family trajectories of men and women in Flanders // Demographic research. 32(31): 859-872. 


\title{
THE USE OF POPULATION REGISTERS FOR RECORDING AND ANALYSIS OF COHABITATION
}

\author{
EKATERINA TRETYAKOVA, ALLA MaKARENTSEVA
}

\begin{abstract}
This paper discusses the possibilities and limitations of using population registers to study the trends of nuptiality, focusing mainly on the registration of different types of cohabitation. The paper describes European practice in recording them (registered partnerships, cohabitation agreements). The article is essentially an overview, revealing the distinctive features of the functioning of modern population registers in developed countries, which are rich in opportunities for researching the demographic behavior of a population. Their advantages include coverage of all the population in the region, up-to-date data and the opportunity for longitudinal analysis of family relations. The authors reveal the main methodological problems of using population registers for the study of cohabitation and the solutions to these problems information about the addresses of people and data about their children in common. The paper identifies the differences in methodology of registers in different countries, for instance registration of foreign citizens.
\end{abstract}

The article presents an overview of foreign research which uses register data for studying the institution of the family: estimates of the prevalence of cohabitation, its duration, factors of formation and dissolution and the impact of type of partnership on reproductive behavior and life expectancy.

Key words: data sources, population registers, marriages, cohabitation.

Ekaterina A. Tretyakova (tretyakova-ea@ranepa.ru), Institute fOr Social ANALYSiS ANd PREDiction, THE Russian Presidential ACAdEMy of NATIONAl Economy and Public Administration, Russia.

Alla O. Makarentseva, Institute for Social Analysis and Prediction, the Russian Presidential Academy of NATIONAL ECONOMY AND PUblic AdMinistration, Russia.

DATE RECEIVED: JUNE 2016.

\section{REFERENCES}

Andrichenko L.V., Meshheryakova M.A. (2012). Informatsionnye registry kak effektivnoe sredstvo sbora i monitoringa dannykh o naselenii [Information registers as an effective tool to collect and control data about population] // Zhurnal rossiyskogo prava [Journal of Russian law]. 8: 16-40.

Baxmetova G. Sh., Isupov A.A. (1999). Registr naseleniya kak sistema demograficheskogo ucheta [Population register as a system of demographic accounting] // Voprosy statistiki [Problems in statistics]. 5: 33-39.

Carlson M., I. Garfinkel, S. McLanahan, R. Mincy, W. Primus (2004). The effects of welfare and child support policies on union formation // Population research and policy review. 23: 513542.

Christiansen S.G., N. Keilman (2013). Probabilistic household forecasts based on register data the case of Denmark and Finland // Demographic research. 28(43): 1263-1302.

Drefahl S. (2012). Do the married really live longer? The role of cohabitation and socioeconomic status // Journal of marriage and family. 74: $462-475$.

Dribe M., M. Stanfors (2009). Does parenthood strengthen a traditional household division of labor? Evidence from Sweden // Journal of marriage and family. 71(1): 33-45. 
Duvander A-Z. E. (1999). The transition from cohabitation to marriage. A longitude study of the propensity to marry in Sweden in the early 1990s // Journal of family issues. 20 (5): 698717.

Haandrikman K., C. Harmsen, L.J.G. van Wissen, I. Hutter (2008). Geography matters: patterns of spatial homogamy in the Netherlands // Population, space and place. 14: 387-405.

Haandrikman K., L.J.G. van Wissen, C. Harmsen (2011). Explaining spatial homogamy. Compositional, spatial and regional cultural determinants of regional patterns of spatial homogamy in the Netherlands // Appl. spatial analysis. 4: 75-93.

Hoem J.M., M. Jalovaara, C. Mureşan (2013). Recent fertility patterns of Finnish women by union status: A descriptive account // Demographic research. 28(14): 409-420.

Holland J.A. (2013). Love, marriage, then the baby carriage? Marriage timing and childbearing in Sweden // Demographic research. 29(11): 275-306.

Isupova O.G. (2013). My prosto zhivem vmeste [We just live together] // Demoskop Weekly [Demoscope Weekly]. №565-566. URL: http://demoscope.ru/weekly/2013/0565/tema01.php (accessed: 22.04.2016).

Ivanova E. I. (2012). Sovremennyy tekushchiy statisticheskiy uchet estestvennogo dvizheniya naseleniya: vozmozhnosti ego primeneniya dlya sotsial'no-demograficheskogo analiza [Modern vital statistics: its application for the socio-demographic analysis] // Vestnik RGGU [Bulletin of RGGU]. 2: 98-112.

Jalovaara M. (2012). Socio-economic resources and first-union formation in Finland, cohorts born 1969-81// Population studies. 66(1): 69-85.

Jalovaara M. (2013). Socioeconomic resources and the dissolution of cohabitations and marriages // European journal of population. 29(2): 167-193.

Kalmijn M., A. Loeve, D. Manting (2007). Income dynamics in couples and the dissolution of marriage and cohabitation // Demography. 44(1): 159-179.

Keilman N., H. Brunborg (1995). Probabilistic household forecasts based on register data- the case of Denmark and Finland // Demographic research. 28(43): 1263-1302.

Klupt M.A., Nikiforov O.N. (2010). Al'ternativnye metody provedeniya perepisey naseleniya: primenimy li oni v Rossii? [Alternative methods of population census conducting: are they applicable in Russia?] // Voprosy statistiki [Problens in statistics]. 9: 3-8.

Koskinen S., K. Joutsenniemi, T. Martelin, P. Martikainen (2007). Mortality differences according to living arrangements // International journal of epidemiology. 36:1255-1264.

Kravdal Ø. (1988). The impact of first-birth timing on divorce: new evidence from a longitudinal analysis based on the central population register of Norway // European journal of population. 4(3): 247-269.

Liu G. (2002). How premarital children and childbearing in current marriage influence divorce of Swedish women in their first marriages // Demographic research. 7(10): 389-406.

Lyngstad T.H. (2004). The impact of parents' and spouses' education on divorce rates in Norway // Demographic research. 10(5): 122-142.

Mäenpää E. (2009). Cohabiting partners' socioeconomic characteristics and the transition to marriage in Finland // Finnish yearbook of population research: 63-77.

Mäenpää E., M. Jalovaara (2013). The effects of homogamy in socio-economic background and education on the transition from cohabitation to marriage // Actasociologica. 56(3): 247-263. 
Mäenpää E., M. Jalovaara (2014). Homogamy in socio-economic background and education, and the dissolution of cohabiting unions // Demographic research. 30(65): 1769-1792.

Martikainen P., T. Martelin, E. Nihtilä, K. Majamaa, S. Koskinen (2005). Differences in mortality by marital status in Finland from 1976 to 2000: analyses of changes in maritalstatus distributions, socio-demographic and household composition, and cause of death // Population studies. 59(1): 99-116.

Neravenstvo i smertnost' v Rossi [Inequality and mortality in Russia] (2000) / V. Shkolnikov, E. Andreev, T. Maleva, eds. M.: Moskovskiy centr Karnegi [Moscow Carnegie center]. 107 p.

Pyankova A.I. (2014). Traditsionnyy i al'ternativnye metody provedeniya perepisey naseleniya [Traditional and alternative methods of population census conducting]: dis. ... kand. sotsiol. nauk. Federal'noe gosudarstvennoe avtonomnoe obrazovatel'noe uchrezhdenie vysshego professional'nogo obrazovaniya «Natsional'nyy issledovatel'skiy universitet «Vysshaya shkola ekonomiki» [Dissertation. National research university "High school of economics"]. Moskow.

Perelli-Harris B., N. Sánchez Gassen (2012). How similar are cohabitation and marriage? Legal approaches to cohabitation across Western Europe // Population and development review. 38(3): 435-467.

Pitkänen K., M. Jalovaara (2007). Perheet ja perheenmuodostus [Family formation]. 2nd renewed edition: $115-168$.

Poulain M., A. Herm (2013). Central population registers as a source of demographic statistics in Europe // Population-E. 68(2): 183-212.

Rønsen M. (2004). Fertility and public policies - evidence from Norway and Finland // Demographic research. 10(6): 143-170.

Sobotka T., L. Toulemon (2008). Overview chapter 4: changing family and partnership behaviour: Common trends and persistent diversity across Europe // Demographic research. 19(6): 85-138.

Statistics of Sweden (2014). URL: http://www.statistikdatabasen.scb.se/ (дата обращения: 23.05.2016).

Svarer M. (2004). Is your love in vain? Another look at premarital cohabitation and divorce // Journal of human resources. 39(2): 523-535.

Thomson E. (2005). Partnership and parenthood: connections between cohabitation, marriage and childbearing // Booth A., Crouter N. The new population problem: why families in developed countries are shrinking and what it means. Mahwah, NJ: Lawrence Erlbaum Associate: 129-149.

Thomson E., H. Eriksson (2013). Register-based estimates of parents' co-residence in Sweden, 1969-2007 // Demographic research. 29(42): 1153-1186.

Vanassche S., M. Corijn, K. Matthijs (2015). Post-divorce family trajectories of men and women in Flanders // Demographic research. 32(31): 859-872. 